\title{
Ambiol Preconditioning Can Induce Drought Tolerance in Abscisic Acid-deficient Tomato Seedlings
}

\author{
Mason T. MacDonald and Rajasekaran R. Lada ${ }^{1}$ \\ Department of Plant and Animal Sciences, Nova Scotia Agricultural College, \\ Cox Institute, P.O. Box 550, Truro, NS B2N 5E3, Canada
}

Jeff Hoyle and A. Robin Robinson

Department of Environmental Sciences, Nova Scotia Agricultural College, Truro, NS, Canada, B2N 5E3

Additional index words. 5-hydroxybenzimidazole, ABA, ABA inhibitor, ABA-deficient, flacca, fluridone, stress tolerance, Solanum lycopersicum L.

\begin{abstract}
Ambiol, a derivative of 5-hydroxybenzimidazole, has been well documented to function as growth promoter, an antistress compound, and an antioxidant when applied as a seed preconditioning agent. However, evidence suggests that Ambiol decreases transpiration and promotes root growth similar to the phytohormone abscisic acid (ABA), leading to the development of the hypothesis that Ambiol promotes drought resistance through an $A B A$-dependent pathway. The effect of $0 \mathrm{mg} \cdot \mathrm{L}^{-1}$ and $10 \mathrm{mg} \cdot \mathrm{L}^{-1}$ was tested on wild-type tomato seedlings (Lycopersicon esculentum Mill. var. Scotia), ABAdeficient flacca tomato seedlings, and ABA-inhibited (with fluridone) tomato seedlings. In both fluridone-treated and flacca seedlings, Ambiol preconditioning resulted in significant increases in shoot growth, root growth, leaf area, and plant height consistent with gains experienced by wild-type tomatoes. In addition, flacca tomatoes experienced increases in photosynthesis and water use efficiency consistent with wild-type tomatoes. Ambiol was able to confer benefits to drought-stressed tomatoes in ABA-deficient and $\mathbf{A B A}$-inhibited conditions, suggesting that Ambiol functions through an $\mathbf{A B A}$ independent pathway.
\end{abstract}

Ambiol [2-methyl-4-(dimethylaminomethyl)5-hydroxy-benzimidazole] is a potent synthetic antioxidant and antistress compound having growth-regulating properties (Darlington et al., 1996; Rajasekaran and Blake, 1999; Rajasekaran et al., 2005; Smirnov et al., 1985). Ambiol was first synthesized by Smirnov et al. (1985) along with several other derivatives of benzimidazole. Ambiol was immediately the focus of several studies for its growth-promoting characteristics. Recent studies by Rajasekaran and Blake (1999) have found that Ambiol protects photosynthesis, membrane damage, enhances water use efficiency, inhibits ethylene synthesis, and sustains new growth in jack pine seedlings under drought. Similarly, BorsosMatovina and Blake (2001) have also found

\footnotetext{
Received for publication 13 July 2009. Accepted for publication 15 Sept. 2009

Funding for this experiment was provided through a scholarship provided by the National Science and Engineering Research Council (NSERC) of Canada.

We thank the C.M. Rick Tomato Genetics Resource Center for their provision of flacca seeds and thank technicians Philip Joy, Azure Adams, and Aru Thiagarajan for their help with equipment. We also thank our colleagues, Drs. Kevin Sibley and Claude Caldwell, for their review of this manuscript.

${ }^{1}$ To whom reprint requests should be addressed; e-mailrlada@nsac.ca.
}

that Ambiol enhances membrane protection and reduces visible damage symptoms in jack pine seedlings after the application of drought stress and low temperatures. Rajasekaran and Blake (2002) made a significant discovery when they found that an Ambiol seed treatment in carrots could increase shoot and root growth (113\% and 214\%, respectively) under drought when compared with the untreated droughted plants, demonstrating strong potential applications in agriculture.

Recent advances have also found that Ambiol is very effective at promoting drought tolerance in tomato seedlings and have focused on understanding the regulatory pathway of Ambiol. MacDonald et al. (2008, 2009) reported that preconditioning with 10 $\mathrm{mg} \cdot \mathrm{L}^{-1}$ Ambiol increased root growth, shoot growth, leaf expansion, photosynthesis, and water use efficiency (WUE) in tomato seedlings under drought stress. It was also found that Ambiol preconditioning invokes certain proteins in the seed, both before and after germination. It was proposed that Ambiol preconditioning first alters the expression of certain genes, sending an (as of yet) unknown signal(s) to elicit a response in the form of membrane protection and increased growth (MacDonald et al., 2009).

One possible signal is abscisic acid $(\mathrm{ABA}) . \mathrm{ABA}$ is a natural phytohormone that is known to regulate various plant growth and developmental processes associated with biotic and abiotic stresses, including drought. Endogenous levels of ABA increase in parallel to water deficit (Wright and Hiron, 1969). ABA's role in stomatal regulation under water deficit has been extensively studied (MacRobbie 1995; Pei et al., 1997; Phillips et al., 1997). ABA is known to control transpiration and increase WUE in plants under drought; thus, ABA accumulation is associated with drought tolerance in many species (Tardieu et al., 1996; Yin et al., 2004). Overexpression of ABA or catalytic enzymes responsible for creating ABA has been shown to enhance drought tolerance of certain crops (Davison et al., 2002). Seed preconditioning using ABA enhances drought and cold tolerance in plants (Minami et al., 2003). The main interest in ABA regarding drought tolerance is in its ability to regulate stomatal apertures and encourage primary root development (Phillips et al., 1997), although ABA has roles in promoting stability of the photosynthetic apparatus (Gong et al., 1998) and gene expression (Chandler and Robertson, 1994).

When applied as a foliar spray, ABA causes alterations in conductance, size, and frequency of stomata in tomato seedlings, suggesting that exogenous application of ABA may aid in drought stress tolerance (Bradford et al., 1983). Bartels et al. (1990) further supported the possibility that exogenous $\mathrm{ABA}$ application of $5 \mathrm{mg} \cdot \mathrm{L}^{-1}$ to an in vitro propagated callus derived from $\mathrm{Cra}$ terostigma plantaginem enhances survival under severe desiccation. Yin et al. (2004) has also found that exogenous application of ABA increases endogenous ABA. Daily spraying of $50 \mu \mathrm{M}$ ABA on poplar leaves decreases transpiration and stomatal conductance $\left(g_{\mathrm{S}}\right)$, enhancing its tolerance to drought stress. However, net photosynthesis and plant growth are negatively affected (Yin et al., 2004). Similar results were found by Rajasekaran and Blake (1999) who found that xylem feeding of ABA increased growth, enhanced root growth, sustained photosynthesis, and increased WUE of jack pine seedlings under drought.

If it is understood that $\mathrm{ABA}$ regulates stomatal aperture to protect plants from drought, is ABA necessary for Ambiol to induce drought tolerance? From the results of MacDonald et al. (2008, 2009), it remains unclear whether the mode of action of Ambiol in promoting drought tolerance requires the presence of $\mathrm{ABA}$ or is independent of $\mathrm{ABA}$, but as a result of similarities in the effects of ABA and Ambiol, it was hypothesized that ABA is required for Ambiol action to enhance drought tolerance. If this is so, inhibiting ABA synthesis will negate the beneficial effects of Ambiol. One candidate to inhibit ABA is fluridone \{1-methyl-3-phenyl-5-[3trifluromethyl(phenyl)]-4-(1H)-pyridinone $\}$, which inhibits phytoene desaturase, an enzyme directly responsible carotenoid biosynthesis (Bartels and Watson, 1978; Vaisberg and Schiff, 1976). There is evidence that carotenoids are precursors to ABA (Zeevaart and Creelman, 1988); thus, any inhibition of 
carotenoids will subsequently inhibit biosynthesis of ABA. Direct measurements of drought-induced $\mathrm{ABA}$ after fluridone treatment confirmed that fluridone inhibits ABA synthesis (Popova, 1995). Alternatively, in ABA-deficient plants, Ambiol will be unable to protect the plants under drought. Flacca is an ABA-deficient tomato mutant having $\approx 25 \%$ of the normal concentration of $\mathrm{ABA}$ (Neill and Horgan, 1985). As a result, this mutant is unable to close stomata and unable to withstand moisture deficits. This mutant should be a useful model to evaluate the role of ABA in Ambiol-induced drought tolerance. The objective of this study was to understand the role of ABA in Ambiolinduced drought tolerance.

\section{Materials and Methods}

Seed preconditioning. All seeds of tomato were preconditioned in the manner described in Rajasekaran and Blake (2002). Tomato seeds were treated by placing $1 \mathrm{~g}$ of seeds into a $250-\mathrm{mL}$ Erlenmeyer flask and soaking with $40 \mathrm{~mL}$ of distilled water containing either $0 \mathrm{mg} \cdot \mathrm{L}^{-1}$ (control) or $10 \mathrm{mg} \cdot \mathrm{L}^{-1}$ Ambiol for 24 h (Ambiol Inc., Toronto, Ontario, Canada). Concentrations of Ambiol were chosen based on the work of MacDonald et al. (2008), which found that $10 \mathrm{mg} \cdot \mathrm{L}^{-1}$ Ambiol preconditioning protected photosynthesis on drought-stressed tomato seedlings while increasing leaf area and dry mass. All flasks were transferred to a G24 Environmental Incubator Shaker (NB Scientific Co. Inc., Edison, NJ) and incubated at $25{ }^{\circ} \mathrm{C}$ and $150 \mathrm{rpm}$ for $24 \mathrm{~h}$. Then the contents of each flask were individually strained and recovered seeds were dried on filter paper at room temperature.

Experimental design. The experiment was set up as a $2 \times 3$ factorial design having five replicates. The first factor was Ambiol concentration $\left(0 \mathrm{mg} \cdot \mathrm{L}^{-1}\right.$ or $\left.10 \mathrm{mg} \cdot \mathrm{L}^{-1}\right)$. The second was ABA status (control, ABAdeficient, and ABA-inhibited). Wild-type tomatoes (var. Scotia) served as the control, a flacca mutant (Prof. C.M. Rick, Tomato Genetics Resource Center, University of California, Davis, CA) served as the ABAdeficient variety, and wild-type tomato seeds treated with $50 \mu \mathrm{M}$ fluridone (Sigma-Aldrich Canada Ltd., Oakville, Ontario, Canada) root soak administered as three daily $250-\mathrm{mL}$ treatments directly before drought served as ABA-inhibited treatment. Plant location in the environment-controlled growth chamber was randomized and rotated daily to minimize the effect of any unknown variables.

Growing conditions. Seeds were first germinated until radicle emergence in a petri dish to ensure viability and then were sown into five $15-\mathrm{cm}$ pots for each treatment combination. Each pot received one seed and served as an experimental replicate. Each pot received $300 \mathrm{~g}$ of Promix BX (Premier Horticulture Inc., Red Hill, PA) and was initially fertilized with $250 \mathrm{~mL}$ of $2.4 \mathrm{~g} \cdot \mathrm{L}^{-1}$ 20N-20P-20K liquid fertilizer (Scotts-Sierra Horticultural Products Company, Marysville, $\mathrm{OH})$.
All plants were grown in an environmentcontrolled growth chamber with a 16-h photoperiod and a combination of fluorescent, incandescent, and sodium lamp lights providing a light intensity of $400 \mu \mathrm{mol} \cdot \mathrm{m}^{-2} \cdot \mathrm{s}^{-1}$. The day/night temperatures were $25 / 16{ }^{\circ} \mathrm{C}$ with a relative humidity of $50 \%$. Plants were grown for $14 \mathrm{~d}$ after emergence under wellwatered conditions, where they received 250 $\mathrm{mL}$ each day. On the 15 th day, drought was imposed by withholding water for $6 \mathrm{~d}$. Final response measurements were taken on the last day of drought.

Moisture. Soil moisture was measured throughout the experiment using a TDR 300 soil moisture probe (Spectrum Technologies, Plainfield, IL) at a depth of $12 \mathrm{~cm}$. Data were expressed as soil moisture before drought $\left(\mathrm{SM}_{0}\right)$ and soil moisture at the end of drought $\left(\mathrm{SM}_{\mathrm{f}}\right)$. Plant moisture was determined gravimetrically using the following formula:

$$
\frac{\text { FreshWeight }- \text { DryWeight }}{\text { FreshWeight }} \times 100
$$

Plant moisture data were expressed as plant moisture of well-watered seedlings $\left(\mathrm{PM}_{\mathrm{w}}\right)$ and plant moisture of droughted seedlings $\left(\mathrm{PM}_{\mathrm{d}}\right)$. Because plant moisture was a destructive measurement, a separate set of well-watered seedlings corresponding to treatment combinations was used to determine $\mathrm{PM}_{\mathrm{w}}$.

Photosynthesis. An LCA4 photosynthetic unit (ADC BioScientific Ltd., Herts, UK) was used to measure photosynthetic parameters (net photosynthesis, instantaneous transpiration, and $g_{\mathrm{S}}$ ) of the newest fully expanded leaf starting at $0900 \mathrm{HR}$ and ending at $1300 \mathrm{HR}$ to minimize diurnal variation. Water use efficiency was calculated as the ratio of photosynthesis to transpiration.
Leaf area. The newest fully expanded leaf was removed from a plant at the end of the experiment after LCA4 measurements were recorded. Each leaf was placed on a white paper backdrop with a reference ruler and photographed from directly overhead. The images of the photographed leaves were uploaded to CIAS 2.0 Image Measurement Software (Jandel Scientific, San Rafael, CA) to calculate actual leaf area.

Chlorophyll index. Chlorophyll index was measured using a Minolta SPAD $504 \mathrm{~m}$ (Minolta, Ramsey, NJ). The Minolta meter was clamped on the newest fully expanded leaf and the transmittance by the leaf at two wavelengths ( $650 \mathrm{~nm}$ and $940 \mathrm{~nm}$ ) was differentially absorbed by chlorophyll (Martinez and Guiamet, 2004).

Membrane injury index. Membrane injury index (MII) was determined using the method described by Odlum and Blake (1996) and uses the percentage of electrolytes leaking into solution to quantify membrane integrity. At the end of drought stress, test tubes were filled with $30 \mathrm{~mL}$ of distilled water and were allowed to adjust to room temperature $\left(25^{\circ} \mathrm{C}\right)$. The electrical conductivity of the distilled water $\left(\mathrm{EC}_{\mathrm{w}}\right)$ alone was measured using a CDM 2e Conductivity Meter (Bach-Simpson, London, Ontario, Canada). Afterward, the newest fully expanded leaf was separated from the stem and completely submerged in a test tube. The tubes were sealed and left at room temperature for $24 \mathrm{~h}$. Initial conductivity $\left(\mathrm{EC}_{\mathrm{o}}\right)$ was measured, which determined the amount of electrolytes leached into solution. Sealed tubes were then placed in a forced-air oven for $4 \mathrm{~h}$ at $90{ }^{\circ} \mathrm{C}$ to kill tissues and then cooled to room temperature. Final conductivity measurements $\left(\mathrm{EC}_{\mathrm{k}}\right)$ were taken after

Table 1. Effect of Ambiol on plant water status and soil moisture of wild type (var. Scotia), ABA-deficient (flacca), and ABA-inhibited tomato (var. Scotia) seedlings before and after drought. ${ }^{\mathrm{z}}$

\begin{tabular}{|c|c|c|c|c|c|c|}
\hline \multirow[b]{2}{*}{ Response } & \multicolumn{2}{|c|}{ Wild type } & \multicolumn{2}{|c|}{ ABA-deficient (flacca) } & \multicolumn{2}{|c|}{ ABA inhibitor (fluridone) } \\
\hline & Control & Ambiol & Control & Ambiol & Control & Ambiol \\
\hline$\overline{\mathrm{SM}_{0}(\%)}$ & $47.4 \mathrm{~b}$ & $50.3 \mathrm{~b}$ & $59.5 \mathrm{a}$ & $59.8 \mathrm{a}$ & $50.0 \mathrm{~b}$ & $58.4 \mathrm{a}$ \\
\hline $\mathrm{SM}_{\mathrm{f}}(\%)$ & $2.8 \mathrm{~d}$ & $2.2 \mathrm{~d}$ & $3.3 \mathrm{~cd}$ & $4.9 \mathrm{~cd}$ & $16.0 \mathrm{c}$ & $9.5 \mathrm{c}$ \\
\hline $\mathrm{PM}_{0}(\%)$ & $91.3 \mathrm{a}$ & $89.6 \mathrm{a}$ & $91.1 \mathrm{a}$ & $90.7 \mathrm{a}$ & $91.0 \mathrm{a}$ & $92.5 \mathrm{a}$ \\
\hline $\mathrm{PM}_{\mathrm{f}}(\%)$ & $87.9 \mathrm{~b}$ & $85.1 \mathrm{~b}$ & $87.5 \mathrm{~b}$ & $86.4 \mathrm{~b}$ & $92.0 \mathrm{a}$ & $91.4 \mathrm{a}$ \\
\hline
\end{tabular}

${ }^{\mathrm{z}}$ Letter groupings indicate significant differences at $\alpha=0.05$ determined using least-squares means comparison.

$\mathrm{ABA}=$ abscisic acid; $\mathrm{SM0}=$ soil moisture before drought; $\mathrm{SMf}=$ soil moisture after drought; PM0 = plant moisture before drought; $\mathrm{PMf}=$ plant moisture after drought.

Table 2. Effect of Ambiol on growth parameters of wild type (var. Scotia), ABA-deficient (flacca), and ABA-inhibited (fluridone) tomato (var. Scotia) seedlings after $6 \mathrm{~d}$ of drought stress imposed by withholding water. ${ }^{\mathrm{z}}$

\begin{tabular}{|c|c|c|c|c|c|c|c|c|c|}
\hline \multirow[b]{2}{*}{ Response } & \multicolumn{3}{|c|}{ Wild type } & \multicolumn{3}{|c|}{ ABA-deficient (flacca) } & \multicolumn{3}{|c|}{ ABA inhibitor (fluridone) } \\
\hline & Control & Ambiol & $\% \Delta$ & Control & Ambiol & $\% \Delta$ & $\overline{\text { Control }}$ & Ambiol & $\% \Delta$ \\
\hline$\overline{\text { Plant height }(\mathrm{cm})}$ & 8.9 & 10.1 & $14^{*}$ & 10.8 & 12.0 & $11 *$ & 6.1 & 8.9 & $45^{*}$ \\
\hline Shoot DM (mg) & 1403 & 1760 & $25^{*}$ & 429.4 & 574.6 & $34 *$ & 337.5 & 538.6 & $60 *$ \\
\hline Root DM (mg) & 660 & 1390 & $110 *$ & 213.6 & 482.9 & $126^{*}$ & 171.6 & 477.5 & $178 *$ \\
\hline Shoot:root & 2.1 & 1.3 & $-40 *$ & 2.0 & 1.2 & $-41 *$ & 2.0 & 1.1 & $-43 *$ \\
\hline Leaf area $\left(\mathrm{cm}^{2}\right)$ & 2.7 & 4.6 & $72 *$ & 0.8 & 1.5 & $82 *$ & 1.5 & 2.9 & $91 *$ \\
\hline MII & 15.9 & 17.8 & 12 & 31.4 & 24.0 & $-31 *$ & 73.5 & 57.2 & $-29 *$ \\
\hline
\end{tabular}

${ }^{\mathrm{z}}$ An asterisk denotes significant difference $(\alpha=0.05)$ between control and Ambiol within each column as determined by contrasts.

$\mathrm{ABA}=$ abscisic acid; $\mathrm{DM}=$ dry matter; $\mathrm{MII}=$ membrane injury index. Leaf area was measured on the newest fully expanded leaf after drought. 
equilibrating to $25^{\circ} \mathrm{C}$ to determine maximum leakage. MII was then calculated using the formula from Odlum and Blake (1996):

$$
M I I=\frac{E C_{o}-E C_{w}}{E C_{f}-E C_{w}} \times 100
$$

Plant height and mass. Plant height was recorded as the height from the cotyledons to the shoot apical meristem of the tomato plant. Afterward, tomato seedlings were gently separated from the soil and then separated into roots and shoot. Each separated portion was placed in a forced-air oven for $24 \mathrm{~h}$ and then the mass was recorded. The shoot and root dry mass was used to determine the shoot:root ratio.

Statistical analysis. Analysis of variance of physiological measurements was completed using SAS 9.1 (SAS Institute, Cary, NC). No interaction effects were observed, so all data were pooled to analyze main effects using contrasts as suggested by Swallow (1984). The effect of $0 \mathrm{mg} \cdot \mathrm{L}^{-1}$ was contrasted with $10 \mathrm{mg} \cdot \mathrm{L}^{-1}$ within the wild-type control, flacca, and fluridone treatments. For moisture measurements, there was interest in measuring whether there was a change after onset of drought, so time (initial and final percent moisture) was introduced as a factor. Thus, moisture measurements were analyzed as a $2 \times 3 \times 2$ factorial. Letter groupings were generated using least-squares means at a $5 \%$ significance level.

\section{Results}

Soil and plant moisture. There was no difference in $\mathrm{SM}_{0}$ between seedlings preconditioned with $0 \mathrm{mg} \cdot \mathrm{L}^{-1}$ and $10 \mathrm{mg} \cdot \mathrm{L}^{-1}$ Ambiol in wild-type or ABA-deficient tomato seedlings. There was, however, significantly higher soil moisture in ABA-inhibited seedlings. Drought significantly decreased the soil moisture in all treatments, but there was no difference in $\mathrm{SM}_{\mathrm{f}}$ between preconditioned with $0 \mathrm{mg} \cdot \mathrm{L}^{-1}$ and $10 \mathrm{mg} \cdot \mathrm{L}^{-1}$ in wild-type, ABAdeficient, or ABA-inhibited tomato seedlings (Table 1).

Decreases in soil moisture corresponded with decreases in plant moisture in most cases. Before drought, plant moisture ranged from $89.6 \%$ to $92.5 \%$. After drought, plant moisture in wild-type and ABA-deficient seedlings dropped by an average of $4.0 \%$. However, there was no change in plant moisture in those seedlings treated with fluridone (Table 1).

Plant growth. Ambiol had a significant effect on plant height under stress in all tomato seedlings. Untreated wild-type tomato seedlings increased from $8.9 \mathrm{~cm}$ to $10.1 \mathrm{~cm}$, flacca seedlings were increased from $10.8 \mathrm{~cm}$ to $12.0 \mathrm{~cm}$, and fluridonetreated seedlings increased from $6.1 \mathrm{~cm}$ to $8.9 \mathrm{~cm}$ as a result of Ambiol preconditioning (Table 2).

Ambiol had a significant effect on both shoot and root dry mass (DM) under stress in all tomato seedlings, which was evident before any quantitative measurements oc- curred (Fig. 1). In wild-type seedlings, shoot DM increased from $1403 \mathrm{mg}$ to $1760 \mathrm{mg}$. In flacca, shoot DM increased from $429.4 \mathrm{mg}$ to $574.6 \mathrm{mg}$. In fluridone-treated seedlings, shoot DM increased from $337.5 \mathrm{mg}$ to 538.6 $\mathrm{mg}$. The effects of Ambiol on root DM were even more dramatic, whereas Ambiol more than doubled root DM in all treatments.
There was an increase of $730.0 \mathrm{mg}$ in wildtype seedlings, $269.3 \mathrm{mg}$ in flacca, and 305.9 $\mathrm{mg}$ in fluridone-treated seedlings. The profound effect of Ambiol on root growth compared with shoot growth is clearly shown in the shoot:root ratio. In all seedlings not preconditioned with Ambiol, the shoot:root ratio is $\approx 2: 1$. In Ambiol preconditioned
(A)

(B)
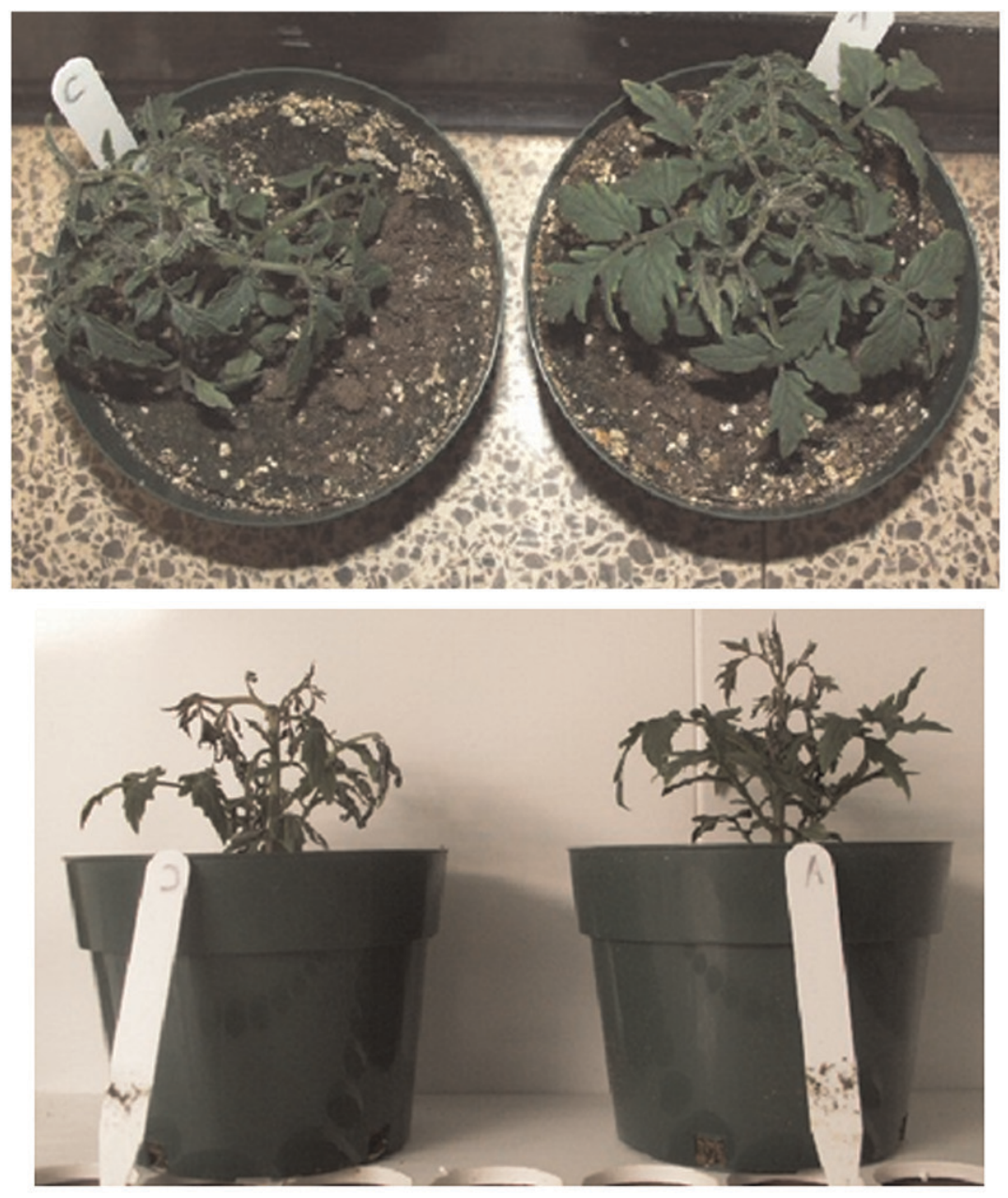

(C)

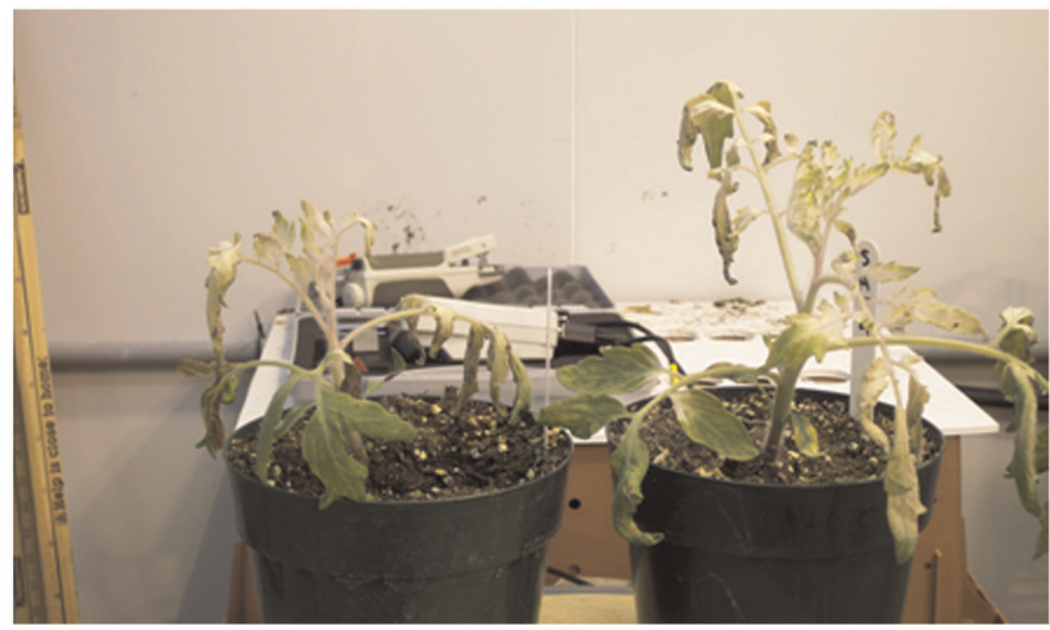

Fig. 1. (A) Top view of $0 \mathrm{mg} \cdot \mathrm{L}^{-1}$ preconditioned wild-type tomato seedlings (var. Scotia) on the left and $10 \mathrm{mg} \cdot \mathrm{L}^{-1}$ preconditioned on the right after drought; (B) side comparison of $0 \mathrm{mg} \cdot \mathrm{L}^{-1}$ preconditioned flacca on the left and $10 \mathrm{mg} \cdot \mathrm{L}^{-1}$ Ambiol-treated flacca on the right after drought; (C) side comparison of $0 \mathrm{mg} \cdot \mathrm{L}^{-1}$ Ambiol-preconditioned fluridone treated tomato seedlings on the left and $10 \mathrm{mg} \cdot \mathrm{L}^{-1}$ Ambiol-preconditioned fluridone treated tomato (var. Scotia) on the right after drought. 
seedlings, that ratio decreased by $\approx 40 \%$ (Table 2).

Ambiol had a significant effect on leaf area of the newest fully expanded leaf under stress in all tomato seedlings. Leaf area of the newest fully expanded leaf increased by $72 \%, 82 \%$, and $91 \%$ in wild-type, flacca, and fluridone-treated seedlings, respectively (Table 2).

Membrane injury and photosynthesis. There was no improvement in MII of wildtype seedlings under stress resulting from Ambiol preconditioning. However, there were significant increases in both flacca and fluridone-treated seedlings. In flacca, MII decreased from 31.4 to 24.0 as a result of Ambiol preconditioning. In fluridone-treated seedlings, MII decreased from 73.5 to 57.2 (Table 2).

Ambiol had no effect on the chlorophyll index under stress in any tomato seedling (Table 3). However, it should be noted that the chlorophyll index was $\approx 75 \%$ lower in fluridone-treated seedlings compared with wild-type and flacca seedlings. Chlorophyll degradation occurred immediately after the fluridone root soak and continued for the duration of the drought period (Fig. 2). This resulted in some problems in measuring photosynthetic parameters in fluridone-treated seedlings. For example, Ambiol preconditioning had a significant effect on net photosynthesis under stress in wild-type and flacca seedlings, increasing by $79 \%$ and $460 \%$, respectively. However, net photosynthesis was below the detectable limit in all seedlings that were treated with fluridone (Table 3 ).

Ambiol had no effect on transpiration in wild-type seedlings, although it did significantly decrease $g_{\mathrm{S}}$ from $0.079 \mathrm{~mol} \cdot \mathrm{m}^{-2} \cdot \mathrm{s}^{-1}$ to $0.021 \mathrm{~mol} \cdot \mathrm{m}^{-2} \cdot \mathrm{s}^{-1}$. However, Ambiol had an opposite effect in flacca; there was no effect on $g_{\mathrm{S}}$, whereas transpiration increased from $0.054 \mu \mathrm{mol} \cdot \mathrm{m}^{-2} \cdot \mathrm{s}^{-1}$ to $0.105 \mu \mathrm{mol} \cdot \mathrm{m}^{-2} \cdot \mathrm{s}^{-1}$. In fluridone-treated seedlings, Ambiol had a significant effect on both transpiration and $g_{\mathrm{S}}$. As a result of Ambiol preconditioning, transpiration increased from $0.026 \mu \mathrm{mol} \cdot \mathrm{m}^{-2} \cdot \mathrm{s}^{-1}$ to $0.078 \mu \mathrm{mol} \cdot \mathrm{m}^{-2} \cdot \mathrm{s}^{-1}$, whereas $g_{\mathrm{S}}$ decreased from $0.023 \mu \mathrm{mol} \cdot \mathrm{m}^{-2} \cdot \mathrm{s}^{-1}$ to 0.009 $\mu \mathrm{mol} \cdot \mathrm{m}^{-2} \cdot \mathrm{s}^{-1}$ in fluridone-treated seedlings (Table 3).

As a ratio of photosynthesis to transpiration, there was no measurement for WUE in fluridone-treated seedlings. However, Ambiol had a significant effect on WUE in both wildtype and flacca seedlings under drought. Water use efficiency increased from 1.699 to 2.669 in wild-type seedlings and increased from 1.000 to 2.886 in $\mathrm{flacca}$.

\section{Discussion}

Ambiol was effective at promoting growth and alleviating drought stress in tomato seedlings. In all tomato seedlings, there was a consistent response with an increase in growth and photosynthesis conferred by Ambiol to tomato seedlings under drought. This was similar to previous studies with tomato seedlings (MacDonald et al., 2008, 2009) as well as other species (Darlington et al., 1996; Islam et al., 2003; Rajasekaran and Blake, 2002) involving other species. Typically, a decrease in transpiration has also been reported in other species, which has often been linked to the drought-mitigating effects of Ambiol. There was no decrease in transpiration in this study or previous Ambiol preconditioning studies with tomato seedlings (MacDonald et al., 2008, 2009). The

Table 3. Effect of Ambiol on photosynthetic parameters of wild-type (var. Scotia), ABA-deficient (flacca), and ABA-inhibited (fluridone) tomato (var. Scotia) seedlings after $6 \mathrm{~d}$ of drought stress imposed by withholding water. ${ }^{z}$

\begin{tabular}{|c|c|c|c|c|c|c|c|c|c|}
\hline \multirow[b]{2}{*}{ Response } & \multicolumn{3}{|c|}{ Wild type } & \multicolumn{3}{|c|}{ ABA-deficient (flacca) } & \multicolumn{3}{|c|}{ ABA inhibitor (fluridone) } \\
\hline & ontrol & Ambiol & $\% \Delta$ & Control & Ambiol & $\% \Delta$ & Control & Ambiol & $\% \Delta$ \\
\hline$\overline{\operatorname{Pn}\left(\mu \mathrm{mol} \cdot \mathrm{m}^{-2} \cdot \mathrm{s}^{-1}\right)}$ & 0.323 & 0.579 & $79^{*}$ & 0.054 & 0.303 & $460^{*}$ & - & - & - \\
\hline$\left.-2 \cdot s^{-1}\right)$ & 0.190 & 0.217 & 14 & 0.054 & 05 & $94 *$ & 0.026 & 0.078 & $56^{*}$ \\
\hline$\left.{ }^{-2} \cdot \mathrm{s}^{-1}\right)$ & 0.079 & 0.021 & $-73 *$ & 0.027 & 30 & 11 & 0.023 & 0.009 & $-61 *$ \\
\hline & & & $57^{*}$ & 1.000 & & 18 & - & - & - \\
\hline Chlorophyll index & 42.00 & 44.32 & 6 & 45.52 & 44.59 & -2 & 7.36 & 2.92 & -60 \\
\hline
\end{tabular}

${ }^{\mathrm{z}}$ An asterisk denotes significant difference $(\alpha=0.05)$ between control and Ambiol within each column as determined by contrasts.

$\mathrm{ABA}=$ abscisic acid; $\mathrm{Pn}=$ net photosynthesis; $\mathrm{Tl}=$ transpiration; $g_{\mathrm{S}}=$ stomatal conductance; $\mathrm{WUE}=$ water use efficiency. Both Pn and WUE were below the detectable limit in ABA-inhibited seedlings.
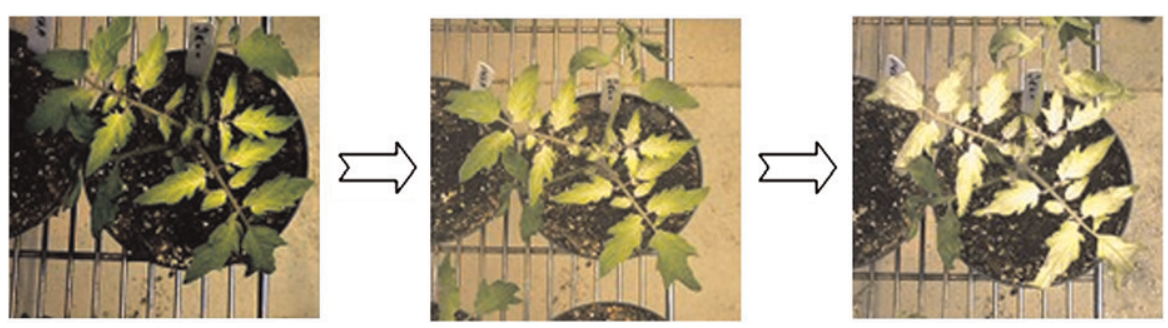

Fig. 2. Progression of chlorophyll degradation in fluridone-treated tomato (var. Scotia) seedlings over a 6-d drought period. Photographs were taken on Says 2, 4, and 6 from left to right. previously reported antitranspirant properties of Ambiol are not pivotal in mitigating drought, although it may provide some benefit to certain species.

More specific to its mode of action, Ambiol protected ABA-deficient flacca tomato seedlings under drought with observed increases in plant growth, photosynthesis, WUE, and membrane stability. Similar results were found using fluridone to inhibit $\mathrm{ABA}$, in which there were significant increases in root DM, shoot DM, leaf area, and plant height under drought. Unfortunately, both photosynthesis and WUE measurements were compromised because fluridone not only inhibits ABA, but also inhibits carotenoid synthesis (Gamble and Mullet, 1986). Carotenoids function to protect the photosynthetic system from photo-oxidative damage. In the absence of chlorophyll, photo-oxidation of chlorophyll caused plant tissue to appear "bleached" (Bartels and Watson, 1978; Devlin et al., 1978). The bleaching effect of fluridone on plant tissue was observed in this experiment thereby limiting some of the most significant benefits promoted by Ambiol. Nonetheless, increases in all plant growth parameters clearly reveal that Ambiol conferred benefits under ABA-inhibited conditions before senescence. Overall, Ambiol was effective at alleviating drought stress without $\mathrm{ABA}$, suggesting the $\mathrm{ABA}$ is not required in the regulatory pathway of Ambiol.

Although it was originally hypothesized that Ambiol would be dependent on ABA (as a result of similarities in promoting drought tolerance), the conferred benefits from Ambiol on ABA-deficient mutants were not completely unexpected. Kirillova et al. (2003) used Ambiol as a foliar spray and found that although growth and photosynthesis were increased by almost $60 \%$, the endogenous levels of ABA decreased by $50 \%$, whereas indoleacetic acid and zeatin increased. Kirillova et al. (2003) suggested that Ambiol may be an ABA inhibitor and, because $\mathrm{ABA}$ is an inhibitor of auxin-related shoot and root growth, Ambiol may indirectly promote auxin and cytokinin production. However, if Ambiol functions as an ABA inhibitor, as suggested by Kirillova et al. (2003), drought-stressed plants treated with Ambiol would have wilted quickly, whereas instead, they experienced increased growth and drought tolerance. It seems more likely that the benefits of Ambiol treatment, especially in promoting root growth, would have helped maintain favorable water balance, perhaps reducing the signal required for ABA in the Kirilova et al. (2003) study. Results from Rajasekaran and Blake (2002) and Islam et al. (2003) provide evidence that Ambiol preconditioning maintains favorable xylem pressure potential and enhances elastic modulus.

There is the possibility that Ambiol is functioning as an antioxidant. Under moderate drought conditions, photosynthesis decreases mainly as a result of stomatal closure, although biochemical constraints may limit 
photosynthetic $\mathrm{CO}_{2}$ fixation as stress continues (Pinheiro et al., 2004). The resulting excess energy is harmful to photosystem II because of overreduction of the photosynthetic electron chain and increased production of reactive oxygen species in the chloroplast (Asada, 1999). Increases in free radicals results in drought-induced membrane lipid peroxidation that destabilizes cellular membranes. The fact that there was a decrease in membrane leakage resulting from Ambiol preconditioning under ABAdeficient and ABA-inhibited conditions supports the premise that Ambiol may act as an antioxidant. It is also possible that the membrane stability is the result of ethylene inhibition, possibility promoted as a result of Ambiol pretreatment, deferring senescence. Ambiol is known to inhibit ethylene production (Rajasekaran and Blake, 1999). A buildup of ethylene under drought may increase membrane leakage, because ethylene is known to increase membrane fluidity in drought-stressed carnations and other types of plants (Abeles et al., 1992; Mayak et al., 1977). However, there have been mixed results in Ambiol-induced membrane protection in the literature as well as this experiment, which saw no membrane protection resulting from Ambiol in wild-type seedlings.

Two conclusions can be made about the regulatory pathway of Ambiol from this experiment. First, Ambiol preconditioning offered similar benefits to root growth, shoot growth, leaf expansion, and plant height in ABA-deficient and ABA-inhibited seedlings when compared with wild-type seedlings grown under drought stress conditions. Ambiol also improved net photosynthesis and WUE in a similar manner when comparing wild-type seedlings with flacca. Evidence strongly supports that $\mathrm{ABA}$ is not necessary for Ambiol to elicit a drought-mitigating effect. Second, the often mentioned antitranspirant properties of Ambiol should not be considered an integral part of Ambiol's regulatory pathway. To further understand how Ambiol exerts its effects, it would be interesting to compare Ambiol preconditioning with exogenous applications of cytokinins and auxins.

\section{Literature Cited}

Abeles, F.B., P.W. Morgan, and M.E. Saltveit. 1992. Ethylene in plant biology. 2nd Ed. Academic Press, San Diego, CA.

Asada, K. 1999. The water-water cycle in chloroplasts: Scavenging of active oxygen and dissipation of excess photons. Annu. Rev. Plant Physiol. Plant Mol. Biol. 50:601-639.

Bartels, D., K. Schneider, G. Terstappen, D. Piatkowski, and F. Salamini. 1990. Molecular cloning of abscisic acid-modulated genes which are induced during desiccation of the resurrection plant Craterostigma plantagineum. Planta 181:27-34.

Bartels, P.G. and C.W. Watson. 1978. Inhibition of carotenoid synthesis by fluridone and norflurazone. Weed Sci. 26:198-203.
Borsos-Matovina, V. and T.J. Blake. 2001. Seed treatment with the antioxidant Ambiol enhances membrane protection in seedlings exposed to drought and low temperatures. Trees (Berl.) 15:163-167.

Bradford, K.J., T.D. Sharkey, and G.D. Farquhar. 1983. Gas exchange, stomatal behaviour, and $\delta 13 \mathrm{C}$ values of the flacca tomato mutant in relation to abscisic acid. Plant Physiol. 72:245250.

Chandler, P.M. and M. Robertson. 1994. Gene expression regulated by abscisic acid and its relation to stress tolerance. Annu. Rev. Plant Physiol. 45:113-141.

Darlington, A., K. Vishnevetskaia, and T.J. Blake. 1996. Growth enhancement and anti-transpirant activity following seed treatment with a derivative of 5-hydroxybenzimidazole (Ambiol) in four drought stressed agricultural species. Physiol. Plant. 96:217-222.

Davison, P.A., C.N. Hunter, and P. Horton. 2002. Overexpression of $\beta$-carotene hydroxylase enhances stress tolerance in Arabidopsis. Nature 418:203-206.

Devlin, R.M., C.N. Saras, M.J. Kisiel, and A.S. Kostusiak. 1978. Influence of fluridone on chlorophyll content of wheat (Triticum aestivum) and corn (Zea mays). Weed Sci. 26:432433.

Gamble, P.E. and J.E. Mullet. 1986. Inhibition of carotenoid accumulation and abscisic acid biosynthesis in fluridone treated dark grown barley. Eur. J. Biochem. 160:117-121.

Gong, M., Y.J. Li, and S.Z. Chen. 1998. Abscisic acid induced thermotolerance in maize seedling is mediated by calcium and associated with antioxidant systems. J. Plant Physiol. 153:488496.

Islam, M.A., T.J. Blake, F. Kocacinar, and L. Rajasekaran. 2003. Ambiol, spermine, and aminoethoxyvinylglycine prevent water stress and protect membranes of Pinus strobus L. under drought. Trees (Berl.) 17:278-284.

Kirillova, I.G., A.S. Evsyunina, T.I. Puzina, and N.P. Korableva. 2003. Effects of Ambiol and 2-chlorethylphosphonic acid on the content of phytohormones in potato leaves and tubers. Appl. Biochem. Microbiol. 39:210-214.

MacDonald, M.T., L.R. Rajasekaran, J. Hoyle, and A.R. Robinson. 2008. Seed pre-conditioning with Ambiol ${ }^{\circledR}$, a derivative of 5-hydroxybenzimidazole, acclimates tomato (Lycopersicon esculentum Mill.) to drought. Acta Hort. 774: 355-362.

MacDonald, M.T., L.R. Rajasekaran, J. Hoyle, and A.R. Robinson. 2009. Seed preconditioning with natural and synthetic antioxidants induces drought tolerance in tomato seedlings. HortScience 44:1323-1329.

MacRobbie, E.A. 1995. ABA-induced ion reflux in stomatal guard cells: Multiple actions of ABA inside and outside the cell. Plant J. 7:565-576.

Martinez, D.E. and J.J. Guiamet. 2004. Distortion of the SPAD 502 chlorophyll meter readings by changes in irradiance and leaf water status. Agronomie 24:41-46.

Mayak, S., Y. Vaadia, and D.R. Dilley. 1977. Regulation of senescence in carnation (Dianthus caryophyllus L.) by ethylene mode of action. Plant Physiol. 54:591-593.

Minami, A., M. Nagao, K. Arakawa, S. Fujikawa, and D. Takezawa. 2003. Abscisic acid-induced freezing tolerance in the moss Physcomitrella patens is accompanied by increased expression of stress related genes. Plant Physiol. 160:475-483.
Neill, S.J. and R. Horgan. 1985. Abscisic acid production and water relations in wilty tomato mutants subjected to water deficiency. J. Expt. Bot. 36:1222-1231.

Odlum, K.D. and T.J. Blake. 1996. A comparison of analytic al approaches for assessing freezing damage in black spruce using electrolyte leakage methods. Can. J. Bot. 74:952-958.

Pei, Z.M., K. Kuchitsu, J.M. Ward, M. Schwarz, and J.I. Schroeder. 1997. Differential abscisic acid regulation of guard cell slow anion channels in Arabidopsis wild-type and abi1 and abi2 mutants. Plant Cell 9:409-423.

Phillips, J., O. Artsaenko, U. Fielder, C. Horstmann, H.P. Mock, K. Muntz, and U. Conrad. 1997. Seed-specific immunomodulation of abscisic acid activity induces a developmental switch. EMBO J. 16:4489-4496.

Pinheiro, H.A., F.M. DaMatta, A.M. Chaves, E.B. Fontes, and M.E. Loureiro. 2004. Drought tolerance in relation to protection against oxidative stress in clones of Coffea canephora subjected to long-term drought. Plant Sci. 167:1307-1314.

Popova, L. 1995. Effect of fluridone on plant development and stress-induced ABA accumulation in Vicia Faba L. plants. Bulg. J. Plant Physiol. 21:42-50.

Rajasekaran, L.R. and T.J. Blake. 1999. New plant growth regulators protect photosynthesis and enhance growth under Jack pine seedlings. J. Plant Growth Regul. 18:175-181.

Rajasekeran, L.R. and T.J. Blake. 2002. Seed pretreatment using a derivative of 5-hydroxybenzimidazole (AMBIOL) pre-acclimates carrot seedlings to drought. Can. J. Plant Sci. 82: 195-202.

Rajasekaran, L.R., A. Stiles, and T.J. Blake. 2005. The effects of natural and synthetic seed preconditioning agents (SPAs) in hastening seedling emergence and enhancing yield and quality of processing carrots. Sci. Hort. 106:25-37.

Smirnov, L.D., Y.V. Kuznetsov, L.G. Stolyarova, and V.P. Lezina. 1985. Aminomethylation of 5-hydroxybenzimidazole. Russ. Chem. Bull. 34:1705-1708.

Swallow, W.H. 1984. Those overworked and oft-misused mean separation proceduresDuncan's, LSD, etc. Plant Dis. 68:919-921.

Tardieu, F., T. Lafarge, and T. Simonneau. 1996. Stomatal control by fed or endogenous xylem ABA in sunflower: Interpretation of correlations between leaf water potential and stomatal conductance in anisohydric species. Plant Cell Environ. 19:75-84.

Vaisberg, A.G. and J.A. Schiff. 1976. Events surrounding the early development of Euglena chloroplasts. 7. Inhibition of carotenoid biosynthesis by the herbicide SAN 9789 [4-chloro-5-methylamino-2-(2, $\alpha, 2$-trifluoro-mtolyl)-3-(2H)-pyridazone] and its developmental consequences. Plant Physiol. 57:260-269.

Wright, S.C. and R.P. Hiron. 1969. Abscisic acid, the growth inhibitor induced in detached wheat leaves by a period of wilting. Nature 224:719720.

Yin, C., B. Duan, X. Wang, and C. Li. 2004. Morphological and physiological responses of two contrasting Poplar species to drought stress and exogenous abscisic acid application. Plant Sci. 167:1091-1097.

Zeevaart, J.A.D. and R.A. Creelman. 1988. Metabolism and physiology of abscisic acid. Annu. Rev. Plant Physiol. 390:439-473. 